\title{
Stem carbohydrate dynamics during post anthesis period in diverse wheat genotypes under different environments
}

\author{
Vidisha Thakur $^{1}$, Girish Chandra Pandey ${ }^{1} \&$ Jagadish Rane ${ }^{{ }^{*}}$ \\ ${ }^{1}$ Department of Bioscience \& Biotechnology, Banasthali Vidyapith, Rajasthan 304 022, India \\ ${ }^{2}$ ICAR-National Institute of Abiotic Stress Management, Malegaon, Baramati, Pune 413115 , India
}

\section{Article history}

Received: 29 November 2019

Accepted: 30 December 2019

Published: 31 December 2019

\section{Publisher}

Horizon e-Publishing Group

\author{
*Correspondence \\ Jagadish Rane \\ 凶Jagadish.Rane@icar.gov.in
}

\begin{abstract}
The contribution of stem water soluble carbohydrates (SWSCs) to grain biomass of wheat ranges from 10 to $20 \%$ under irrigated condition and 40 to $60 \%$ under stresses such as terminal heat and drought. Genetic variation in SWSC and its mobilization can be useful to increase the grain yield of wheat under harsh environments. Hence, a set of 16 genotypes varying in spike morphology and grain yield was grown in field under timely sown, late sown and terminal drought stress conditions. The anthrone method was used to measure the SWSC concentration in the dried peduncle and penultimate internodes in three replicates at 3 growth stages starting from anthesis. The effect of delay in sowing and terminal drought on the SWSC concentration was significant from anthesis to 14 days after anthesis. Significant genetic variation was observed in the rate of post anthesis change in SWSC during the early grain filling period under the three conditions which partially contributed to the variation in grain yield per spike among the genotypes. Due to sterile florets and/or shorter grain filling duration, all the genotypes did not have a correlation between grain weight per spike and rate of decrease of SWSCs. Thus, our experiments reconfirm the significance of SWSC in present cultivars of wheat and also the scope for exploiting the genetic variation in this trait.
\end{abstract}

Keywords: Stem water soluble carbohydrates; spike morphology; anthesis; terminal heat stress; terminal drought stress

Citation: Thakur V, Pandey G C, Rane J. Stem carbohydrate dynamics during post anthesis period in diverse wheat genotypes under different environments. Plant Science Today 2019;6(sp1):556-559. https://doi.org/10.14719/pst.2019.6.sp1.688

Copyright: (C) Thakur et al. (2019). This is an open-access article distributed under the terms of the Creative Commons Attribution License, which permits unrestricted use, distribution, and reproduction in any medium, provided the original author and source are credited (https://creativecommons.org/licenses/by/4.0/).

Indexing: Plant Science Today is covered by Scopus, Web of Science, BIOSIS Previews, ESCI, CAS, AGRIS, UGC-CARE, CABI, Google Scholar, etc. Full list at http://www.plantsciencetoday.online

\section{Introduction}

Wheat crop often gets exposed to drought and high temperature during grain growth particularly in subtropical conditions $(1,2)$. The adverse effect of drought and heat stress mainly results from decrease in kernel number per spike and grain yield $(3,4)$. The post anthesis photosynthesis is reduced under stress, consequently grain filling depends more on the stem reserves remobilization
(5-7). SWSC contribute from 10 to $20 \%$ of the grain weight under favourable conditions $(8,9)$ and as much as 40 to $100 \%$ depending on environment and genotype (10). Recent studies have reported up to $60 \%$ contribution of SWSC in wheat under stress $(6$, 11).

The SWSC remobilization depends on growth stages, environmental conditions and genotypes. Heat $(12)$ or water stress $(13,14)$ can 
reduce the SWSC content. Under heat stress, there is an increase in mobilization efficiency and thus plants can partially compensate for reduced stem carbohydrates content (12). A reduction in plant water status and photosynthesis caused by drought stress induces the conversion of stored reserves into soluble (transportable) sugars and their transport to grains $(6,15)$. In wheat, the mechanism of stored SWSC remobilization to grain under stressed and non-stressed condition is unclear as both positive (16) and negative relationships (17) have been observed. Hence, the present study was carried out to identify the importance of the SWSC mobilization to grains in under favourable and stressed conditions in diverse wheat genotypes.

\section{Materials and Methods}

\section{Field experiment}

Triticum aestivum L. genotypes varying in their spike morphology were sown in $2 \mathrm{~m}^{2}$ plots in three replicates under three conditions: timely sown, late sown and terminal drought in randomised complete block design in the field of Krishi Vigyan Kendra, Banasthali Vidyapith $\left(26^{\circ} 24^{\prime} \mathrm{N}, 7^{\circ} 47^{\prime} \mathrm{E}\right)$, in the Tonk district of Rajasthan, which comes under the Northern Plain and Central highlands including Aravallis (4.2) according to Agro Ecological Sub Regions by ICAR. The area is prone to regular drought and occasional heat waves. Timely sowing was done on 20-11-2018 and late sowing was followed after 23 days. The anthesis stage of early and late flowering genotypes was synchronized by the difference of sowing time by 7 days accordingly. The soil NPK was 224.3, 33.06 and $362.88 \mathrm{Kg} /$ ha respectively, $\mathrm{pH}$ mildly alkaline (7.92) and the micronutrients were present in sufficient concentration. Recommended levels of urea $(120 \mathrm{Kg} / \mathrm{ha})$, and DAP (60 Kg/ha) were used. Pest and weed control performed according to usual local practices and recommendations. The drought was imposed by withholding the irrigation and temporary rain out shelter during the reproductive phase of growth. The daily maximum and minimum temperature and relative humidity were recorded during the growth period.

\section{Estimation of SWSC}

The peduncle and penultimate internode of the main stem were collected from each plot at anthesis, 7 days after anthesis (DAA) and 14 DAA. The main stems were selected based on their development being earliest in order. The samples were dried in oven at $70{ }^{\circ} \mathrm{C}$ for $48 \mathrm{hr}$. The SWSC were extracted from $0.1 \mathrm{~g}$ sample by grinding in liquid nitrogen followed by incubation with $8 \mathrm{ml}$ ethanol at $80^{\circ} \mathrm{C}$ for $1 \mathrm{hr}$ and two extractions with 8 $\mathrm{ml}$ water at $80{ }^{\circ} \mathrm{C}$ for $1 \mathrm{hr}$ each. The extracts were used for SWSC measurement using anthrone method (18).

\section{Phenotypic measurements}

The grain number per spike and the number of spikelets per spike were measured in three spikes from each treatment of genotypes. The days to anthesis and maturity were recorded for each genotype. At maturity, 3 main spikes for each genotype and treatment were threshed manually and the grain yield/ spike was measured.

\section{Statistical analysis}

Statistical significance was computed by the analysis of variance using R software version 3.6.

\section{Results}

The SWSC during the time period from 0 to 14 DAA was significantly affected by the delay in sowing and terminal drought. Genetic variation was observed for the SWSC under the timely sown, late sown and terminal drought treatments. There was also a notable effect of genotype and environmental interaction on the SWSC concentration at all the three stages (Table 1). The SWSC increased under the non-stressed conditions, but gradually decreased under both the stresses during the early grain filling (Fig. 1).

Table 1. Analysis of variance for SWSCs

\begin{tabular}{|c|c|c|c|}
\hline Parameter & Source of variation & DF & Mean squares \\
\hline \multirow{4}{*}{$\begin{array}{c}\text { SWSCs at } 0 \\
\text { DAA }\end{array}$} & Genotypes & 15 & $21719.7^{* * *}$ \\
\hline & Treatment & 2 & $3672.9 * * *$ \\
\hline & Genotype X Treatment & 30 & $115.4^{* * *}$ \\
\hline & Residual & 96 & $28.9 * * *$ \\
\hline \multirow{4}{*}{$\begin{array}{c}\text { SWSCs at } 7 \\
\text { DAA }\end{array}$} & Genotypes & 15 & $19557.8^{* * *}$ \\
\hline & Treatment & 2 & $14354.8^{* * *}$ \\
\hline & Genotype X Treatment & 30 & $128.7^{* * *}$ \\
\hline & Residual & 96 & $24.8^{* * *}$ \\
\hline \multirow{4}{*}{$\begin{array}{c}\text { SWSCs at } 14 \\
\text { DAA }\end{array}$} & Genotypes & 15 & $22622^{* * *}$ \\
\hline & Treatment & 2 & $32579 * * *$ \\
\hline & Genotype X Treatment & 30 & $271^{* * *}$ \\
\hline & Residual & 96 & $76^{* * *}$ \\
\hline
\end{tabular}

* Significant at $P=0.05$; ${ }^{* *}$ significant at $P=0.01,{ }^{* * *}$ significant at $P=0.001$

The grain number/spike, number of spikelets/spike and grain yield/spike were significantly affected by terminal heat and drought stress. Also, the genotypes had significant differences in these parameters under all the three environmental conditions. The grain growth duration was significantly reduced in some of the genotypes such as PBW 175, HD 2987 and Raj 4079 under the late sown condition and in case of sunstar and chinese spring under the terminal drought stress. 
In AKAW 4627, the average SWSC content was 1.43 fold higher than local check Raj 3765 under all three treatments. The rate of decrease of SWSC was 2 fold and 1.6 fold higher in AKAW 4627 under drought and late sown conditions, respectively along with higher yield as compared to the local cultivar Raj 3765.

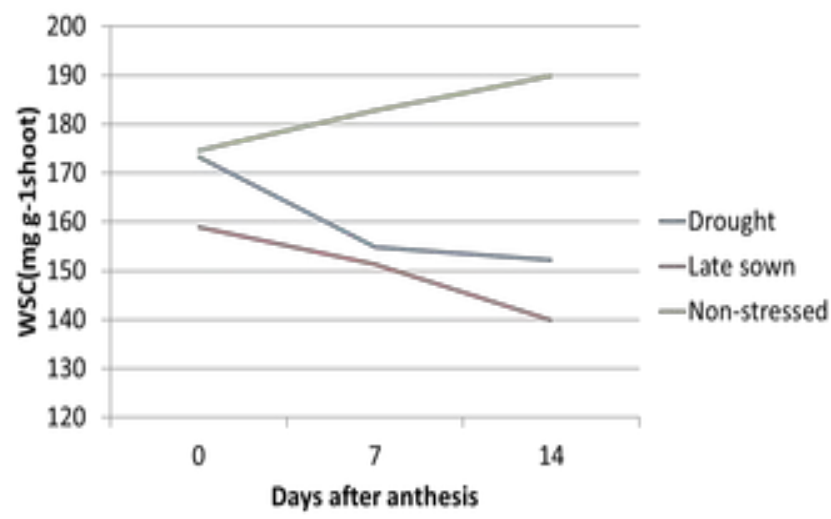

Fig. 1. The trend of SWSC from 0 DAA to 14 DAA during terminal drought, irrigated late sown and non-stressed (Irrigated timely sown) conditions.

\section{Discussion}

The correlation of grain yield with SWSCs gets weakened when the grain formation gets affected by stress and not the grain filling. If the carpels inside the floret are not fertilized, the grain formation process itself gets affected and even if there is sufficient SWSC, it may not be useful.
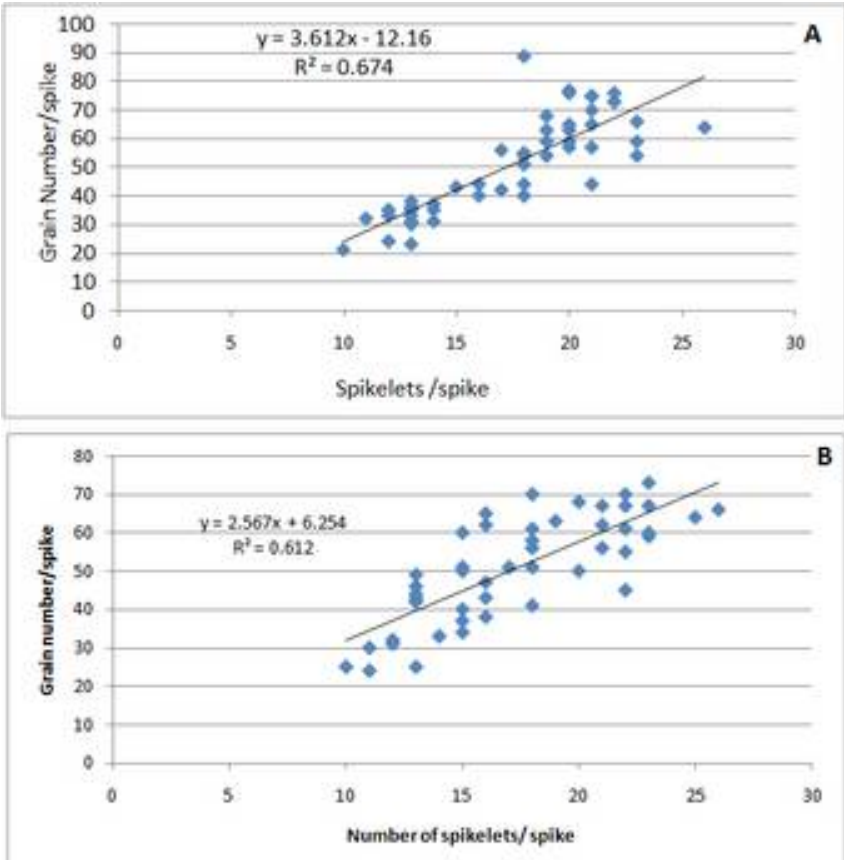

Fig. 2. The genotypes having correlation between the grain number/spike and Spikelet no./spike under (A) the late sown condition and (B) drought condition

Only $67 \%$ and $61 \%$ of the data reveals an association between grain number and spikelet per spike under the late sown and drought condition respectively (Fig. 2). Spikes of some genotypes must have failed to form grains and there was no scope for grain filling even if there is sufficient remobilization. Another speculation is that spike might have not got sufficient time for filling even if there are sufficient SWSC. As the grain filling duration of some genotypes such as Chinese spring and MP 4010 were shorter, their grain weight/spike is not correlated to SWSC.
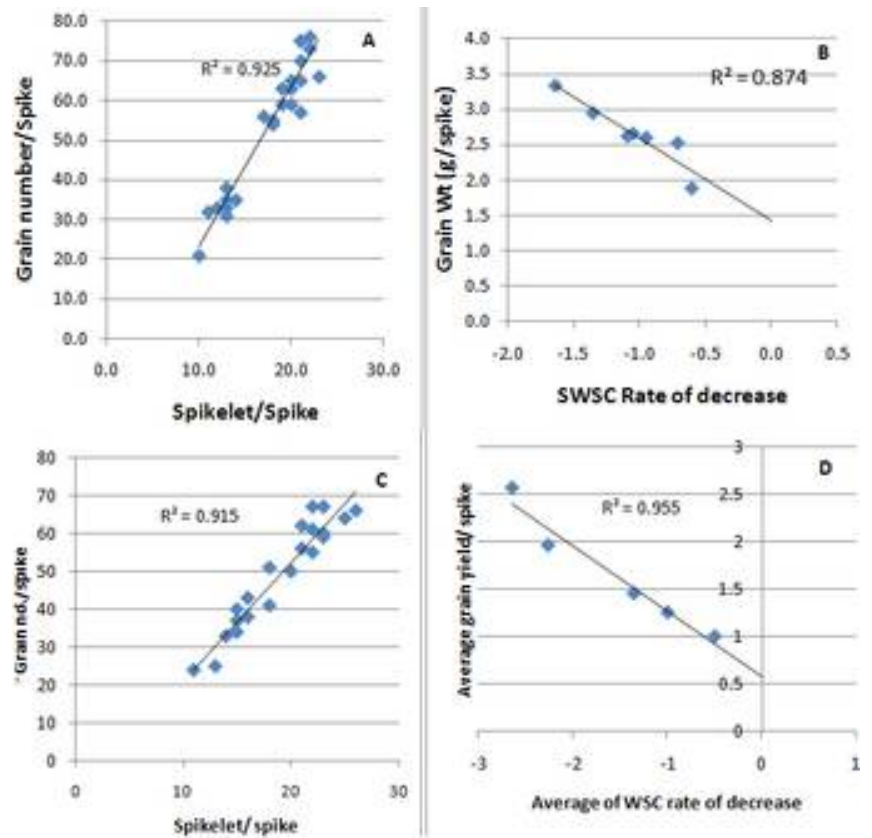

Fig. 3. (A) Spikelet/spike correlated to grain no./spike for LS (late sown) condition, (B) Grain wt./spike correlated to SWSC rate of decrease under LS condition, (C) Spikelet/spike correlated to grain no./spike for drought condition, (D) Grain wt./spike correlated to SWSC rate of decrease under drought stress

Thus, the association between the rate of decline in SWSC after anthesis and the grain $\mathrm{wt} /$ spike was analysed with only those set of spikes where grain no. per spike is correlated well with spikelets per spike. Therefore, the grain wt/spike had a positive correlation $\left(\mathrm{R}^{2}=0.87\right.$ under late sown and $\mathrm{R}^{2}=0.955$ under terminal drought stress) in the genotype set with proper grain formation (Fig. 3).

In the present study a recent, terminal heat stress tolerant variety AKAW 4627 stores higher amount of SWSC and has a higher rate of SWSC mobilization contributing to higher grain yield per spike as compared to old local late sown cultivar Raj 3765. Earlier studies have also stated that the high temperature stress during grain filling increases the amount of SWSC remobilized to grains by $60 \%$ and different genotypes show variation for its remobilization $(12,19,20)$.

\section{Conclusion}

Genetic variation exists among the wheat cultivars for SWSC remobilization under terminal heat and drought stress. The rate of SWSC mobilization during early grain filling is significantly correlated to grain yield in a group of genotypes that exhibited grain weight proportional to the number of spikelets per spike. The recent variety AKAW 4627, has higher SWSC and its mobilisation to the grains along with higher yield as compared to local popular cultivars such as Raj 3765 . Thus, this study 
reconfirms the significance of SWSC in present cultivars of wheat and also the scope for exploiting the genetic variation in this trait.

\section{Authors' contributions}

VT is associated with data generation under field and lab condition. Manuscript was evaluated by JR and GCP helped with germplasm selection and field sowing.

\section{Acknowledgements}

The authors acknowledge the Director, ICAR-Indian Institute of Wheat \& Barley Research, Karnal for providing wheat germplasm. The authors are grateful to Prof. Aditya Shastri, Vice Chancellor, Banasthali Vidyapith for providing all necessary support. We acknowledge the Bioinformatics Center, Banasthali Vidyapith supported by DBT for providing computation support, and DST for providing networking and equipment support through the FIST and CURIE programs at the Department of Bioscience and Biotechnology. CESME, Banasthali Vidyapith, supported by MHRD, Government of India under the PMMMNMTT is acknowledged for organizing the symposium.

\section{References}

1. Rane J, Mishra B, Shoran J, Pannu R K, Sohu V S, Saini R S, et al. Performance of Yield and Stability of Advanced Wheat Genotypes under Heat Stress Environments of the Indo-Gangetic Plains. Crop Sci. 2007; 47:1561-73.

2. Reynolds M P, Singh R P, Ibrahim A, Ageeb O A, Larqué-Saavedra A, Quick J S. Evaluating physiological traits to compliment empirical selection for wheat in warm environments. Euphytica 1998; 100:85-94.

3. Dencic S, Kastori R, Kobiljski B, Duggan B. Evaluation of grain yield and its components in wheat cultivars and landraces under near optimal and drought conditions. Euphytica 2000; 113:43-52.

4. Estrada-Campuzano G, Slafer G A, Miralles D. Differences in yield, biomass and their components between triticale and wheat grown under contrasting water and nitrogen environments. Field Crop Res. 2012; 128:167-79.

5. Blum A. Improving wheat grain filling under stress by stem reserve mobilization. Euphytica 1998; 100:77-83.

6. Plaut Z, Butow B J, Blumenthal C S, Wrigley C W. Transport of dry matter into developing wheat kernels and its contribution to grain yield under post-anthesis water deficit and elevated temperature. Field Crops R. 2004; 86:185-98.
7. Dreccer M F, Barnesa L, Mederb R. Quantitative dynamics of stem water soluble carbohydrates in wheat can be monitored in the field using hyperspectral reflectance. Field Crops Res. 2014; 159:70-80.

8. Gebbing T, Schnyder H. Pre-anthesis reserve utilization for protein and carbohydrate synthesis in grain of wheat. Plant Physiol. 1999; 121(3):871-78.

9. Vignjevic M, Wang X, Olesen J, Wollenweber B. Traits in spring wheat cultivars associated with yield loss caused by a heat stress episode after anthesis. J Agron Crop Sci. 2015; 201:32-48.

10. Van Herwaarden A, Angus J F, Richards $R$ A, Farquhar G D. 'Haying-off', the negative grain yield response of dryland wheat to nitrogen fertiliser. II: Carbohydrate and protein dynamics. Aust J Agri Res. 1998; 49:1083-93.

11. Rebetzke G J, van Herwaarden A F, Jenkins C, Weiss M, Lewis D, Ruuska S, et al. Quantitative trait loci for soluble stem carbohydrate production in wheat. Aust J Agri Res. 2008; 59: 891-905.

12. Wang X, Cai J, Liu F, Jin M, Yu H, Jiang D, et al. Pre anthesis high temperature acclimation alleviates the negative effects of post anthesis heat stress on stem stored carbohydrate remobilization and grain starch accumulation in wheat. J Plant Physiol. 2012; 55: 331-36.

13. Ehdaie B, Alloush G A, Waines J G. Genotypic variation in linear rate of grain growth and contribution of stem reserves to grain yield in wheat. Field Crops Res. 2008; 106:34-43.

14. Gupta A, Kaur K, Kaur N. Stem Reserve Mobilization and Sink Activity in Wheat under Drought Conditions. American J Plant Sci. 2011; 2:70-77.

15. Yang J C, Zhang J H, Wang Z Q, Zhu Q S, Wang W. Remobilization of carbon reserves in response to water deficit during grain filling of rice. Field Crops Res. 2001; 71:47-55.

16. Foulkes M J, Snape J W, Shearman V J, Reynolds M P, Gaju O, Sylverstar-Bradley R. Genetic progress in yield potential in wheat: recent advances and future prospects. J Agric. Sci. 2007; 145:17-29.

17. Zhang J, Chen W, Dell B, Vergauwen R, Zhang X, Mayer J E, et al. Wheat genotypic variation in dynamic fluxes of WSC components in different stem segments under drought during grain filling. Front Plant Sci. 2015; 6:624.

18. Yemm E W, Willis A J. The estimation of carbohydrates in plant extracts by anthrone. Biochem J. 1954; 57(3):508-14.

19. Zamani M M, Nabipour M, Meskarbashee M. Stem water soluble carbohydrate remobilization in wheat under heat stress during the grain filling. Int J Agric Biol. 2014; 16:401-05.

20. Tahir I S A, Nakata N. Remobilization of nitrogen and carbohydrate from stems of bread wheat in response to heat stress during grain filling. J. Agron. Crop Sci. 2005; 191:106-15. 